\title{
Lagunas en el Derecho y casos irrelevantes
}

\section{Legal Gaps and Irrelevant Cases}

Pablo E. Navarro

\begin{abstract}
Autor:
Pablo E. Navarro

CONICET, Argentina

pabnav@hotmail.com

Recibido: 25-6-2019

Aceptado: 27-11-2019

Citar como:

Navarro, Pablo E., (2020). Lagunas en el Derecho y casos irrelevantes. Doxa. Cuadernos de Filosofía del Derecho, 43, pp. 159-187. https://doi.org/ 10.14198/DOXA2020.43.07

Licencia:

Este trabajo se publica bajo una Licencia Creative Commons Atribución 4.0 Internacional.

\section{(c) (1)}

(c) Pablo E. Navarro

\begin{abstract}
Resumen
En este trabajo analizo las principales diferencias entre las lagunas normativas y otros tipos casos que el derecho no regula. Sin embargo, las lagunas normativas son casos jurídicamente relevantes porque el derecho intenta regularlos y no proporciona una solución. La teoría jurídica tradicional ha tratado de distinguir las lagunas normativas de otros casos irrelevantes, que son aquellos que el derecho «no regula ni tiene la intención de regular». Además, la teoría tradicional ha argumentado que la diferencia entre las lagunas normativas y los casos irrelevantes es de naturaleza evaluativa; que las lagunas son 'algo más' que casos sin solución. Siguiendo a Alchourrón y Bulygin, defiendo una concepción objetiva y neutral de las lagunas normativas, pero señalo una cierta ambigüedad en la conocida teoría de ambos autores, que afecta especialmente la distinción entre lagunas y casos irrelevantes. También critico la propuesta de Ruiz Manero, que ofrece un enfoque alternativo a la concepción objetiva. Finalmente, elaboro un criterio de distinción entre lagunas normativas y casos irrelevantes que explica en qué sentido una determinada acción pertenece a la esfera extranormativa.
\end{abstract}

Palabras claves: Discreción judicial; permisiones; sistemas jurídicos abiertos.

\begin{abstract}
In this paper I analyze the main differences between legal gaps and other type of unregulated cases. Traditional legal theory often distinguishes normative gaps from other irrelevant cases, which are those that the law 'does not regulate or intend to regulate'. In addition, traditional theory claims that the difference between normative gaps and irrelevant cases is of an evaluative nature; that gaps in the law are 'something more' than cases without a solution. In other words, the concept of a normative gap would lack semantic autonomy. Following Alchourrón and Bulygin I defend an objective and neutral conception of normative gaps, but I point out a certain ambiguity in the well-known theory of both authors, which especially
\end{abstract}


affects the distinction between gaps and irrelevant cases. I also criticize the proposal of Ruiz Manero, which offers an alternative approach to the objective conception. Finally, I elaborate a criterion of distinction between normative gaps and irrelevant cases that explains in which sense a certain action belongs to the extra-normative sphere.

Keywords: Judicial discretion; permissions; open legal systems.

\section{INTRODUCCIÓN}

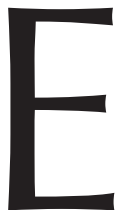

n la teoría jurídica es frecuente asumir que el derecho tiene límites. Sin embargo, los filósofos del derecho persistentemente discrepan acerca de la ubicación y naturaleza de esos límites. Esos desacuerdos no son controversias acerca de la existencia de ciertos fenómenos, sino más bien sobre nuestra comprensión de ellos. Tal vez, esta perplejidad no es una situación extraña en filosofía y, por ello, es útil recordar los comentarios de von Wright acerca del análisis de ciertas ideas de sentido común.

Las opiniones filosóficas que niegan cosas que todos damos por sentado, incluso los filósofos cuando no filosofan, deben ser rechazadas por absurdas o sin sentido... Con ello, sin embargo, el filosofar acerca de esas cosas no encuentra su final... El problema, sin embargo, no es con la verdad de las opiniones y afirmaciones de sentido común, sino con su significado... Responder a tales cuestiones es la tarea del análisis. ${ }^{1}$

Siguiendo esta recomendación de von Wright, podríamos preguntarnos qué significa asumir que el derecho tiene límites. En principio, aceptamos -incluso cuando filosofamos acerca del derecho- que las autoridades de un sistema jurídico positivo dictan un conjunto limitado de normas a lo largo de la historia institucional de una comunidad y que esas normas jurídicas se refieren expresamente solo a un número finito de acciones humanas genéricas. Este hecho podría ser considerado como el núcleo de la tesis de los límites. La verdad de esta intuición compartida no será aquí puesta en duda, pero es importante comprender que el significado de esta tesis permanecerá indeterminado hasta que no se analicen las consecuencias que se siguen de esa idea indisputable.

En este trabajo analizaré la tensión subyacente a dos consecuencias de la tesis de los límites. Por una parte, usualmente se afirma que el derecho puede tener lagunas normativas y que esas situaciones tienen que ser discrecionalmente resueltas por los jueces. Por otra parte, con frecuencia se acepta que el derecho positivo es una función de las decisiones de las autoridades normativas y los eventos que están fuera de ese marco de decisiones (i.e., se encuentran 'más allá de los límites del sistema jurídico) se producen en un 'espacio libre' de derecho. En ese espacio ocurren una infinidad de acontecimientos socialmente irrelevantes, e.g., el movimiento del dedo meñique, el

1. Von Wright, G.H., 1995, p. 30. 
beber leche en el desayuno, la elección de un lugar de vacaciones, etc. Estas situaciones son casos irrelevantes que el derecho no regula y, sin embargo, no parece obvio que, por su simple ausencia de regulación expresa, ellos tengan que ser resueltos mediante decisiones discrecionales. En otras palabras, no solo parece inapropiado exigir una autorización jurídica expresa para que esas conductas puedan ser libremente realizadas por los individuos, sino que también resulta extraño sostener que los jueces pueden discrecionalmente disponer de esa esfera extranormativa.

Ahora bien, ¿qué determina si una situación sin regular es un caso irrelevante o una laguna normativa? Una conocida respuesta es que las lagunas son casos que deberían tener una solución. Por ejemplo, según Soeteman²,

La cuestión acerca de si existe una laguna es, sin embargo, una cuestión valorativa: se refiere a si el conflicto de intereses en verdad no ha recibido atención y a si la consecuencia de ello es que se ha equivocadamente omitido dictar ciertas normas o normas más específicas.

La consecuencia principal de esa visión es que el concepto de laguna normativa carecería de autonomía semántica ya que su referencia no podría determinarse sin el desarrollo de un argumento evaluativo ${ }^{3}$. Por consiguiente, el contenido y los límites del derecho (el universo de casos jurídicamente regulados) no dependerían únicamente de hechos sociales, sino que, en verdad, también requeriría de una evaluación de esos hechos.

A efectos de mantener mi análisis dentro de unos márgenes razonablemente precisos, revisaré las relaciones entre lagunas normativas, casos irrelevantes y discrecionalidad judicial a la luz de las teorías de Alchourrón y Bulygin. A su vez, revisaré una propuesta contemporánea, formulada por Juan Ruiz Manero, que distingue de manera novedosa entre casos irrelevantes y lagunas normativas. Mi conclusión será que la propuesta de Ruiz Manero debe ser rechazada y que, con ciertos ajustes, la teoría de Alchourrón y Bulygin puede dar cuenta una buena respuesta al problema de los casos irrelevantes.

\section{EL ALCANCE DEL DERECHO POSITIVO}

Parece evidente que existe una irremediable divergencia entre el número limitado de normas que pueden crear las autoridades de un cierto sistema jurídico y las infinitas conductas que los individuos pueden ejecutar en esa comunidad. Aunque cualquier conducta puede estar expresamente prohibida o permitida, es imposible que cada una de las posibles acciones de los miembros de esa comunidad esté regulada por una norma específica del sistema. En este sentido, Tony Honoré pregunta ${ }^{4}$ :

2. Soeteman, 1989, pp. 137-138.

3. Acerca de la noción de autonomía semántica, véase, Schauer, 1991, pp. 53-62.

4. HoNORÉ, 1987 , p. 1. 
... ¿cómo pueden ser completos los sistemas jurídicos? ¿Dónde está ese código inagotable mediante el que el Estado, después de producirse un evento, clasifica a la conducta de los ciudadanos como correcta o incorrecta?

Como respuesta a estos interrogantes, Honoré afirma lo siguiente ${ }^{5}$ :

Si en el mundo real los sistemas jurídicos son completos, su completitud no depende de la pretensión de que la solución a cada problema pueda ser conocida anticipadamente. Más bien reside en el hecho de que el sistema tiene los recursos para suministrar una solución a cada problema. Los recursos disponibles consisten, por supuesto, en primer lugar, en reglas y principios. Pero aun ellos conjuntamente pueden ser insuficientes... las reglas y principios del sistema tienen que ser complementados por una cruda decisión. Los jueces, no menos que los legisladores y administradores, pueden tener que decidir.

No cuestionaré aquí esta manera de entender la completitud, que antes que negar las lagunas jurídicas, más bien destaca esas carencias del sistema y la necesidad de decisiones discrecionales ${ }^{6}$. Creo que el principal problema del argumento de Honoré es que se apoya en dos presupuestos dudosos. Por una parte, los sistemas cerrados son inflexibles porque los jueces carecen de autoridad para cambiar el derecho y resolver los problemas axiológicos derivados de soluciones injustas, pero jurídicamente válidas. Por otra parte, la creación de un sistema completo sería una cuestión de elección (algo así como un recurso de técnica legislativa); es decir, sería el resultado de un balance realizado por las autoridades entre la inflexibilidad y la discreción y, por consiguiente, una decisión a favor de imponer una regla de clausura o, en cambio, de preservar una esfera extra-normativa.

Ambos presupuestos pueden ser cuestionados. Por ejemplo, Kelsen ofrece una visión muy diferente de la relación entre completitud y discreción judicial. A lo largo de la evolución de la Teoría Pura del Derecho, Kelsen modificó varios aspectos centrales de su doctrina, pero mantuvo siempre una enfática negativa a admitir la existencia de lagunas en el derecho. Pero, a diferencia de Honoré -que considera a los sistemas completos como 'inflexibles' y a la discreción judicial como un último recurso para solucionar casos sin resolver en sistemas completos en sentido débil- Kelsen admite sin reparos la completitud del derecho y señala que las lagunas normativas son solo una ficción jurídica destinada a encubrir que los jueces pueden modificar el sistema jurídico en casos de soluciones axiológicamente inadecuadas ${ }^{7}$.

\footnotetext{
5. HONORÉ, 1987, p. 29.

6. Una posición parecida a la de Honoré puede encontrarse en Atienza, 2009, pp. 113-115. Para Atienza, la existencia de una laguna depende no solo del material que ofrece el legislador sino también de la actividad de los intérpretes y jueces. Así, él ofrece un enfoque 'dinámico' de las lagunas y se compromete con el descubrimiento de las respuestas correctas que ofrecen las razones subyacen a las diferentes normas formuladas. De ese modo, a diferencia de Honoré, Atienza niega el papel discrecional -creador de derecho- que desempeñan los jueces en casos difíciles. Véase pp. 121-123 del trabajo citado arriba.

7. Kelsen, 1979, p. 256.
} 


\section{KELSEN, LAS LAGUNAS EN EL DERECHO Y LA CLAUSURA NORMATIVA}

Kelsen reconoce que un 'mínimo de libertad' es consustancial al orden jurídico ya que por medido de acciones específicas, el derecho solo puede obligar a ciertas y determinadas acciones y omisiones ${ }^{8}$. Por esa razón, señala?:

...el orden jurídico puede limitar en más o en menos la libertad humana, en cuanto obliga a más o menos. Pero un mínimo de libertad, es decir, de independencia jurídica, una esfera de la existencia humana en que ningún orden o prohibición interviene, permanece siempre resguardada.

Sin embargo, el mínimo inevitable de libertad es compatible con la completitud del derecho porque las acciones que no han sido previstas por las autoridades también están jurídicamente reguladas. Según Kelsen, una conducta que no está expresamente prescripta por una norma jurídica, está negativamente regulada y ello significa que es una acción negativamente permitida ${ }^{10}$. En este sentido, las lagunas en el derecho son imposibles ya que toda conducta está expresamente prescripta o negativamente permitida ${ }^{11}$. Más aún, no tiene sentido afirmar que las autoridades jurídicas pueden dejar intencionalmente sin resolver jurídicamente una determinada situación porque, con independencia de sus decisiones, las conductas siempre serán positiva o negativamente reguladas por el derecho. Por consiguiente, los sistemas jurídicos son órdenes completos, pero esta característica no impide la discreción judicial ni la creación judicial de derecho.

Kelsen presenta sus conclusiones como una respuesta a la 'teoría tradicional' ${ }^{12}$, según la cual el sistema jurídico no es aplicable a un caso concreto cuando ninguna norma general se refiere a ese caso; por consiguiente, los jueces están obligados a completar la laguna mediante la creación de la correspondiente norma ${ }^{13}$. La 'teoría tradicional' asume que el mínimo de libertad es inevitable ya que no es posible regular expresamente a cada posible situación, pero ello compromete a encontrar un criterio para distinguir entre casos sin regular que pueden ser discrecionalmente resueltos por los jueces (i.e., lagunas normativas) y aquellos otros casos irrelevantes que no tiene sentido regular y que tampoco admiten soluciones discrecionales. Por ejemplo, Fernando Atria señala ${ }^{14}$ :

8. Kelsen, 1979, p. 56.

9. Kelsen, 1979, p. 57.

10. Kelsen, 1979, p. 56.

11. Kelsen, 1979, pp. 55 y 254.

12. Es conveniente advertir que la expresión 'teoría tradicional' requiere cierta cautela ya que se refiere a una manera de agrupar a opiniones coincidentes acerca de las lagunas normativas, pero que se articulan en contextos filosóficos sustancialmente diferentes. Para un panorama general de esta manera 'tradicional' de entender a las lagunas jurídicas, véase, Larenz, 1980, 363-374. También, véase, Ramos Pascua, 2017, pp. 50-57.

13. Kelsen, 1979, p. 255.

14. Atria, 2005, p. 67. También, véase, Soeteman, 1989, pp. 138 y 141. 
Si el caso llevado ante el juez es uno que no interesa al derecho, el juez no tiene discreción, aunque no esté el caso regulado, y debe desechar la excepción. Si el caso es uno que sí interesa al derecho pero que no está regulado, entonces el juez tiene discreción y debe crear una regla.

Esta posición, sin embargo, solo es sostenible si es posible formular un criterio para determinar el conjunto de casos que el derecho pretende regular, un criterio que nos permita distinguir casos no regulados pero que el derecho pretende regular, y casos no regulados pero que el derecho no pretende regular. La función de este criterio es crucial, porque solo el primer tipo de casos constituirían lagunas que darían discreción al juez. Pero el derecho no tiene estados mentales, y "pretender» es algo que solo figurativamente puede hacer. El argumento... es que solo argumentos normativos (morales), que deben su valor no a estar basados en fuentes, sino a que son correctos, permiten hacer esta distinción. Los casos que el derecho pretende solucionar son los casos que, en la mejor interpretación, el derecho debe pretender solucionar.

Sin embargo, los esfuerzos para precisar claramente los límites de ambas clases de casos sin regular no han obtenido suficiente consenso. En este sentido, Alchourrón y Bulygin señalan ${ }^{15}$ :

No es de extrañar que frente a esta situación, bastante lamentable, otros pensadores hayan optado por cortar el nudo gordiano, negando totalmente la existencia de lagunas normativas, que no serían -en su opinión- más que otras tantas ficciones tendientes a ocultar el hecho de que los juristas (y, en especial, los jueces) -encubriendo con el piadoso manto de la ciencia sus valoraciones políticas y éticas-, proclaman la necesidad de llenar una laguna cuando en realidad pretenden alterar el derecho existente. El representante más notable de esta tendencia es, sin duda, Hans Kelsen. ${ }^{16}$

Parece una exageración afirmar que Kelsen niega la existencia de lagunas en el derecho porque pretenda evitar las confusiones entre cuestiones conceptuales y valorativas, que habitualmente infectarían a la teoría tradicional. Más bien, su crítica a la teoría tradicional es básicamente que ella pasa por alto un hecho peculiar: los jueces siempre pueden decidir una controversia aplicando el derecho. Para Kelsen ${ }^{17}$,

Lo que no está jurídicamente prohibido, está jurídicamente permitido. Al rechazar el tribunal la demanda, o absolver al acusado, el tribunal aplica el orden jurídico que permite al demandado o acusado aquella conducta en cuyo respecto se ha orientado la demanda o querella no fundada en el orden jurídico.

Sin embargo, por 'aplicación del derecho' en los supuestos casos de lagunas normativas es posible entender dos cosas diferentes, que marcan la evolución del pensamiento kelseniano ${ }^{18}$. En una primera etapa, esa aplicación está ligada a la existencia de una 'norma negativa', contenida en cualquier sistema jurídico, que permite negativamente

15. Alchourrón, Carlos y Bulygin, Eugenio, 1974, p. 165.

16. Alchourrón y Bulygin luego añaden que esta solución radical que Kelsen ofrece al problema de las lagunas oculta las importantes diferencias existentes entre diversos desacuerdos valorativos subyacentes a la identificación y aplicación del derecho. Véase, Alchourrón, Carlos y Bulygin, Eugenio, 1974, p. 165.

17. Kelsen, 1979, p. 252.

18. Al respecto, véase, Alchourrón, Carlos y Bulygin, Eugenio, 1974, pp. 184-188. 
las conductas que las otras normas no han prohibido ${ }^{19}$. Pero esta respuesta a la teoría tradicional presupone que existe necesariamente una norma de clausura en cualquier sistema jurídico y ello contradice la misma idea de contingencia que caracteriza al derecho positivo ${ }^{20}$.

Tal vez por esa razón antes mencionada, en la segunda edición de la Teoría pura, la respuesta a la teoría tradicional es más elusiva ${ }^{21}$ :

... Cuando el orden jurídico no estatuye ninguna obligación a cargo de un individuo, su comportamiento está permitido. La aplicación del orden jurídico no es lógicamente imposible en el caso en que la teoría tradicional supone una laguna. Puesto que, si bien en el caso de que no sea posible la aplicación de una norma jurídica aislada, es posible en cambio la aplicación del orden jurídico, y ello también constituye aplicación de derecho. La aplicación del derecho no está lógicamente excluida.

En esta reconstrucción, Kelsen parece asumir que un rasgo estructural del derecho (de cualquier derecho positivo) es que protege una esfera de libertad que no ha sido expresamente prevista en la medida en que exige a los jueces que desechen las pretensiones que carecen de fundamento. Por ello, si un individuo A reclama ante el juez que otro individuo $\mathrm{B}$ sea obligado a realizar una determinada acción, pero ninguna norma jurídica respalda esa exigencia, entonces el juez debe rechazar la demanda. Sin embargo, como señalan Alchourrón y Bulygin, parece extrańo sostener que un juez rechaza una demanda porque no puede aplicar al caso en cuestión ninguna norma jurídica válida y, al mismo tiempo, afirmar que ese rechazo constituye una aplicación del orden jurídico en general ${ }^{22}$.

A pesar de las diferencias entre (y las deficiencias de) las dos explicaciones que Kelsen ofrece de la expresión 'aplicación del derecho', ellas comparten una idea común: la completitud de los sistemas jurídicos es algo más que un mero ideal racional. Más bien, su tesis es que, por su propia naturaleza, los sistemas carecen de lagunas. En este sentido, A. Wilson señala que para Kelsen, la completitud ${ }^{23}$ :

... no es tanto una afirmación empírica como una exigencia filosófica que surge de la creencia de que la base de un sistema jurídico no puede ser expandida más allá del punto en que se agotan las fuentes positivas del derecho.

Esta creencia es la que juega un papel central en la idea de que no hay casos que carezcan de regulación jurídica. Sin embargo, hay, al menos, dos razones para revisar esta creencia.

Por una parte, Kelsen conecta la discusión sobre las lagunas con el problema de la clausura del orden jurídico. Por ejemplo, en su Teoría general de las normas, sostiene $e^{24}$ :

19. Véase, por ejemplo, Kelsen, 1992, p.85.

20. Alchourrón, Carlos y Bulygin, Eugenio, 1974, pp. 185-186.

21. Kelsen, 1979, p. 255.

22. Alchourrón, Carlos y Bulygin, Eugenio, 1974, p. 187.

23. WiLson, 1994, p. 153.

24. Kelsen, 1991, 131. 
Si distinguimos entre la regulación positiva y negativa de la conducta humana, toda conducta de una persona sujeta a un ordenamiento jurídico está jurídicamente regulada, ya sea positiva o negativamente. En este sentido, podemos hablar de la clausura del orden jurídico.

Por el contrario, si se admitiese que el derecho no regula todos los casos imaginables, podría analizarse qué significa y en qué circunstancias es asumible la distinción entre sistemas normativos abiertos y cerrados ${ }^{25}$. Esta división carecería de sentido si se asumiese que todos los casos (aparentemente) sin regular también están permitidos y, correlativamente, la tesis de los límites del derecho (al menos en el sentido de que hay casos que están más allá de lo que el derecho dispone) carecería de interés.

Por otra parte, las acciones que no están positivamente reguladas (es decir, aquellas que el derecho permitiría negativamente) son prácticamente innumerables y su relevancia jurídica depende de factores heterogéneos. Por esa razón, sería mejor rechazar que el derecho regula aquellas conductas que simplemente no ha prohibido y elaborar una tipología más fina de los casos que el derecho no regula. En esa tipología habría que incluir las siguientes categorías:

1) Lagunas normativas: Son casos sin solución que, a pesar de su indudable importancia, el derecho no soluciona. Así, podría decirse que las lagunas normativas son casos sin solución, aunque el derecho pretende regularlos. Para resolver este tipo de situaciones, es usual señalar que los jueces tienen que crear discrecionalmente derecho.

2) Casos irrelevantes: Son casos que el derecho no pretende regular (e.g., el movimiento del dedo meñique). Estos casos carecen de importancia social y nadie espera que el derecho los autorice expresamente para recién entonces incorporarlos a su ámbito de libertad.

En líneas generales, el problema de los casos irrelevantes se refiere a las respuestas jurídicas en circunstancias en las que ciertas conductas ajenas al espacio regulado por el derecho producen una colisión de intereses. Comportamientos tales como sonreír, efectuar reparaciones en el interior nuestra propiedad o escoger un lugar de vacaciones son ejemplos de innumerables acciones que nadie espera que el derecho regule, pero es fácil imaginar situaciones en las que una sonrisa permanente afecta a otro individuo ${ }^{26}$, un muro en nuestra propiedad afecta las preferencias de nuestro vecino ${ }^{27}$, o escoger Francia como lugar de descanso genera un conflicto en una pareja de recién casados ${ }^{28}$.

La respuesta natural a esos conflictos en casos irrelevantes es rechazar la injerencia de las instituciones jurídicas en ese espacio libre de regulación normativa. Así, si un caso es clasificado como irrelevante o poco serio, entonces el juez simplemente desechará

25. Von Wright, G.H., 1968, p. 85. Alchourrón, Carlos y Bulygin, Eugenio, 1974, pp. 169-171.

26. Véase, Dworkin, 1977, p. 102.

27. Kelsen, 1979, p. 56.

28. Atria, 2005, p. 17.

Doxa. Cuadernos de Filosofía del Derecho, (2020), 43, pp. 159-187 
la demanda que carece de fundamento ${ }^{29}$. Esos casos irrelevantes no resultan en creación judicial de derecho mientras que la solución de las lagunas normativas supone una oportunidad para que los jueces introduzcan discrecionalmente nuevas normas jurídicas. De ese modo, una vez que se admite que el derecho tiene límites (i.e., que no regula cualquier situación posible), surge el problema de los casos irrelevantes y del alcance de la discreción judicial.

El problema de la demarcación de casos irrelevantes reintroduce la pregunta que la teoría clásica pretendía responder: ¿es necesario utilizar un criterio valorativo para distinguir entre lagunas y casos irrelevantes? Las respuestas a este desafío pueden agruparse en dos grandes líneas de análisis. Por una parte, una concepción objetiva, defendida por autores que insisten en la posibilidad de identificar neutralmente las lagunas normativas y, por tanto, niegan que la filosofía del derecho o la ciencia jurídica tenga necesidad de embarcarse en la búsqueda de un criterio valorativo para distinguir entre diferentes tipos de casos que el derecho no ha regulado. Por otra parte, una concepción evaluativa, defendida por autores que retoman el enfoque de la teoría clásica, insistiendo en que las lagunas normativas son algo más que casos sin solución. Conforme a estas reconstrucciones, el concepto de laguna normativa carece de autonomía semántica ya que no podemos identificar a qué circunstancias se refiere sin desplegar un razonamiento evaluativo.

En las próximas secciones analizaré esta propuesta con cierto detalle.

\section{LA CONCEPCIÓN OBJETIVA DE LAS LAGUNAS NORMATIVAS}

Un ejemplo paradigmático de la concepción objetiva se encuentra en numerosos trabajos de Eugenio Bulygin (y Carlos E. Alchourrón). En líneas generales, para Bulygin la discusión acerca de las lagunas es relativa al modo en que un determinado sistema $S_{\mathrm{n}}$ resuelve un problema normativo específico. Esta simple enunciación del contexto que da sentido a la discusión de las lagunas impone dos restricciones importantes. En primer lugar, el debate acerca de las lagunas no se plantea como una cuestión filosófica genérica ya que no tiene sentido discutir acerca de la existencia de lagunas en abstracto (e.g., ¿hay lagunas en el derecho?). Más bien, la controversia tiene que acotarse a un problema concreto (e.g., ¡tiene lagunas la nueva regulación del código civil argentino relativa a la reivindicación de bienes inmuebles?) En segundo lugar, la discusión sobre las lagunas normativas es acerca de la completitud de un micro-sistema de normas válidas que regulan el problema normativo, i.e., no es una controversia acerca del 'ordenamiento jurídico' en general ${ }^{30}$.

Un problema normativo está definido por una correlación entre un determinado universo del discurso y un universo de acciones. Solo una vez que se identifica esa

29. BuLYGin, 2005, p. 83.

30. Alchourrón, Carlos y BulYgin, Eugenio, 1974, p. 121. 
correlación tiene sentido analizar el modo en que un micro-sistema $S_{n}$ resuelve a todos los casos relevantes para ese problema. Los casos relevantes son, en principio, una función de las propiedades mencionadas por las normas del sistema y la combinación de esas propiedades 'encapsula' ('recorta') el espacio de situaciones que el derecho 'regula y pretende regular'. Las lagunas normativas se producen solo en el interior de ese espacio normativamente determinado y este ámbito puede ser neutralmente identificado en el mismo sentido en que es posible una identificación objetiva del derecho de una comunidad (i.e., normas que surgen de fuentes sociales). Así, la identificación de los casos relevantes no depende de las valoraciones del intérprete o el juez, sino únicamente de las normas válidas del sistema. Por consiguiente, el criterio para distinguir entre casos irrelevantes y lagunas normativas no depende del desarrollo de argumentos morales sino de la identificación de un determinado conjunto de propiedades, i.e. la tesis de relevancia de un sistema normativo $S_{n}$.

La clase complementario de la tesis de relevancia de un determinado sistema normativo (para un determinado problema normativo) está formado por propiedades irrelevantes ya que su presencia o ausencia no determina una diferencia en el status normativo que el sistema atribuye a una cierta acción ${ }^{31}$. Esas propiedades irrelevantes, sin embargo, no determinan 'casos irrelevantes', que el derecho no regula ni pretende regular. Más bien, la adición de otras propiedades a la tesis de relevancia, aunque ellas no hayan sido expresamente previstas por la autoridad, no produce lagunas, pero el intérprete de las normas (e.g., el juez) puede valorar esas propiedades de manera diferente al modo en que surge de las soluciones del micro-sistema seleccionado. En ese caso las valoraciones del intérprete (i.e., la hipótesis de relevancia) es más fina que la tesis de relevancia. Estas complicaciones producidas por las diferencias entre tesis e hipótesis de relevancia suministran el contexto en el que surgen las denominadas 'lagunas axiológicas ${ }^{32}$.

Aunque esta reconstrucción de Bulygin ofrece un buen punto de partida, su propuesta no es completamente satisfactoria ya que no consigue trazar una clara diferencia entre los casos de lagunas y los casos irrelevantes de la esfera extranormativa. No hay dudas en que la extensión de la esfera extranormativa depende de la amplitud de la regulación normativa. Al respecto, Alchourrón y Bulygin señalan que 'el conjunto de actos no regulados depende, naturalmente de los actos regulados, esto es, de los cambios en el sistema normativo en cuestión. Pero esto no es una razón para tratar los actos no regulados como si lo estuvieran'. Esta última puntualización está dirigida a marcar una diferencia en las consecuencias que surgen cuándo una acción está expresa o implícitamente autorizada por una norma permisiva y otras consecuencias que se producen

31. En un breve, pero influyente, trabajo publicado hace varias décadas, Ricardo Caracciolo cuestiona el modo en que Alchourrón y Bulygin identifican a las propiedades relevantes ya que, en su opinión, esa identificación encierra una valoración y, por consiguiente, no sería adecuado asumir que una laguna normativa puede ser identificada de manera objetiva y neutral. Véase, CARACCIOLO, 1994, pp. 25-34. Una respuesta a la objeción de Caracciolo puede encontrarse en Rodríguez, 2002, pp. 82-87.

32. Véase, Alchourrón, Carlos y Bulygin, Eugenio, 1974, pp. 157-167. 
cuándo ella no ha sido regulada. En el último caso, pero no en el primero, hay lugar para una decisión discrecional. De este modo, Alchourrón y Bulygin responden a quienes no creen necesario trazar una distinción entre una autorización (facultamiento) y la ausencia de regulación normativa. En esa respuesta, los autores argentinos analizan diversas situaciones posibles a la luz de las diferentes regulaciones que puede recibir una acción en un sistema normativo. La primera de esas situaciones es un supuesto en que una acción p y su complementaria (i.e., $\sim$ p) pertenecen a la esfera extranormativa, es decir a un ámbito que está más allá de lo que regula el sistema normativo. $\mathrm{Al}$ respecto señalan ${ }^{33}$ :

No existe en el sistema $\alpha$ ninguna norma referente a p o $\sim$; tanto p como $\sim$ p no están regulados: ambos pertenecen a la esfera extranormativa. Ambos están permitidos en sentido débil (= no están prohibidos). El sistema es incompleto con respecto a p y $\sim$ p.

Ahora bien, afirmar que las conductas no reguladas de la esfera extranormativa están débilmente permitidas al igual que están débilmente permitidas las acciones en casos de lagunas puede resultar en una triple confusión. En primer lugar, en el concepto de laguna que se utiliza; en segundo lugar, en el rango de significación del concepto de permiso débil y, finalmente, en el alcance de la discrecionalidad y la creación judicial de derecho.

\section{a) Conceptos absolutos y relativos de lagunas normativas}

Anteriormente he destacado que Bulygin acepta la distinción entre diferentes situaciones que carecen de regulación jurídica. En su opinión ${ }^{34}$,

Sería ciertamente extraño pensar que toda conducta no regulada constituye una laguna normativa. Hay infinitas conductas no reguladas por el derecho, que nadie calificaría como lagunas.

Sin embargo, al afirmar que cuando las acciones $\mathrm{p}$ y $\sim \mathrm{p}$ pertenecen a la esfera extranormativa, el sistema es incompleto, parece asumirse que la falta de regulación de esas conductas también ejemplifica supuestos de lagunas en el derecho.

Las proposiciones verdaderas acerca de la existencia de lagunas normativas dan cuenta de situaciones internas a un conjunto de circunstancias que la autoridad ha intentado resolver (i.e., universo de casos relevantes) ${ }^{35}$. Por ello, cuando se afirma que un sistema normativo es incompleto con relación a la esfera extranormativa se introduce otro concepto más general de laguna, ya que no se refiere a ningún conjunto específico de acciones sino a cualquier acción posible de la esfera extranormativa. Ambos

33. Alchourrón, Carlos y BulYgin, Eugenio, 1991, p. 229.

34. Bulygin, 2005, p. 83.

35. No abordaré aquí el problema relativo a las lagunas normativas que se producen en otros universos de casos diferentes al universo de casos relevantes. Al respecto, véase Alchourrón, Carlos y Bulygin, Eugenio, 1974, pp. 193-196. 
conceptos de completitud ya están presentes en el ensayo seminal sobre lógica de nomas y proposiciones normativas de Carlos Alchourrón. En ese ensayo, él ofrece una reconstrucción del concepto absoluto de completitud, conforme al cual un sistema es completo cuando determina normativamente a cualquier acción posible. Sin embargo, inmediatamente después de esa definición añade que 'normalmente, esa exigencia resultará demasiado fuerte; lo que se requiere en la mayoría de los casos no es la determinación de todo $p$ posible, sino tan solo la determinación de todas las proposiciones de un cierto conjunto ${ }^{36}$.

El concepto restringido es el que ocupa el lugar principal en el clásico libro Normative Systems. En ese análisis se señala que los sistemas jurídicos son completos cuando toda solución maximal posible está lógicamente implicada o excluida para cada caso elemental. En otras palabras, si UC es un universo de casos elementales y US es el Universo de soluciones maximales correspondientes a una acción R, en un sistema completo puede probarse OR o OR para cada caso elemental de UC. Este rasgo es, para Alchourrón y Bulygin, la característica más importante de la completitud normativa. Sin embargo, esta notable propiedad de las correlaciones deductivas que un sistema de normas ofrece para un US y UC nada dice acerca del estatus deóntico de otras acciones independientes. Salvo que exista una regla de clausura en el ordenamiento, los sistemas normativos serán siempre incompletos respecto del conjunto de acciones pertenecientes a la esfera extranormativa. Por ello, a efectos de preservar la idea de que la completitud es un rasgo contingente de los sistemas normativos, es conveniente desvincular la esfera extranormativa (que es un problema externo al ordenamiento jurídico) de las eventuales lagunas de un micro-sistema jurídico (que es un problema interno al modo en que ciertas normas jurídicas regulan un determinado conjunto de casos y acciones).

\section{b) El rango de significación del concepto de permisión débil}

Una propiedad P es aplicada en su rango de significación cuando tiene sentido afirmar de un cierto objeto que posee o carece de P. Según von $\mathrm{Wright}^{37}$,

El rango de una propiedad también puede ser denominado como su rango de significación. Si una cierta cosa no tiene ni carece de una cierta propiedad, entonces la atribución de esa propiedad a esa cosa 'no tiene sentido' o 'carece de significado'.

El número 7, por cierto, no es valiente. Esto no significa, sin embargo, que carezca de valor, que es un cobarde. Significa solo que los números no pertenecen al rango de significación de atribución de rasgos de carácter a algo.

Siguiendo esta idea de von Wright, puede sostenerse que el rango de significación de la expresión 'débilmente permitido' abarca a una correlación de circunstancias y

36. Alchourrón, 1991, pp. 41-42.

37. Von Wright, 1984, p. 43.

Doxa. Cuadernos de Filosofía del Derecho, (2020), 43, pp. 159-187 
acciones evaluadas por un determinado sistema de normas. Si se admite que una propiedad p es relevante en un cierto caso de un universo de casos UC con relación a una acción $\mathrm{R}$, entonces parece oportuno limitar el rango de significación de 'débilmente permitido' a esos conjuntos de casos UC y la acción R. En otras palabras, solo una vez que se identifica a un determinado sistema $S$ y un determinado problema normativo, tiene sentido preguntarse acerca del alcance de las conductas débilmente permitidas. Este es el contexto (o rango de significación) apropiado para evaluar, por ejemplo, el extraordinario descubrimiento de Carlos Alchourrón de la equivalencia entre permisos fuertes y débiles en sistemas normativos completos y coherentes. Por ello, no tendría sentido señalar que ese teorema es inútil porque los sistemas son siempre incompletos respecto a las conductas de la esfera extranormativa y que, por consiguiente, siempre habría conductas que están débilmente permitidas, pero no fuertemente autorizadas. Ese es también el contexto apropiado para señalar que en casos de una única norma que obliga a realizar p (i.e., Op), esa acción está regulada y, al mismo tiempo, está débilmente permitida. Pero, esa conclusión sería imposible en la esfera extranormativa ya que esas conductas, por hipótesis, carecen de regulación. Por ello, parece oportuno sostener que en la esfera extranormativa una conducta no está débilmente permitida, pero que de allí no se sigue que ella está prohibida.

\section{c) El alcance de la discrecionalidad y la creación judicial de derecho}

Bulygin (con Alchourrón) ha mostrado claramente la relevancia de las normas permisivas en contextos jerárquicamente estructurados y el sentido que adquiere en esos contextos la autorización expresa de conductas que no han sido previamente reguladas ${ }^{38}$. Por ello, esos permisos son diferentes a la 'indiferencia' correspondiente a los casos no regulados. Pero esas distinciones tienen que complementarse con una clara separación entre la esfera extranormativa de casos no regulados y las lagunas normativas. En caso contrario (i.e., si no hubiese diferencias entre lagunas y casos no regulado), parecería inevitable concluir que los casos no regulados tienen las mismas consecuencias que corresponden a la solución de las lagunas normativas. Por ello, con independencia de si los jueces tienen discreción o deben rechazar la demanda en casos irrelevantes, es importante clarificar los límites de la creación discrecional de derecho por parte de los jueces en la solución de lagunas normativas.

Por 'creación judicial de derecho' se entiende la formulación de una nueva norma general por parte de los jueces, que sirve de fundamento a la parte dispositiva del conflicto en casos de lagunas. A su vez, una norma general es 'novedosa' cuando su contenido no es derivable de otras normas del sistema normativo ${ }^{39}$. Ahora bien, podría ser cierto que un micro-sistema $S$, compuesto solo por normas, $\mathrm{N} 1$ y N2, fuese incompleto

38. Véanse, Alchourrón, Carlos y Bulygin, Eugenio, 1991, pp. 215-218 y 219-248,

39. Acerca de la creación judicial de normas generales, véase Bulygin, 1991, pp. 355-370. 
porque no regula una cierta acción $\mathrm{R}$ en un caso relevante $\mathrm{y}$, al mismo tiempo, podría ser falso que $\mathrm{R}$ carezca de regulación en ese caso porque otras normas en vigor en el ordenamiento jurídico, e.g., N3, proporciona una solución a ese caso. Al respecto, es importante subrayar dos cosas. Por una parte, aunque el caso sin regular ejemplifique un caso de lagunas, la acción $\mathrm{R}$ no pertenece a la esfera extranormativa ya que ella se encuentra regulada por las normas $\mathrm{N} 1$ y N2, aun cuando esas normas no ofrezcan una solución para esa acción $\mathrm{R}$ en un caso específico de cierto universo de casos. Por otra parte, incluso ese caso que las normas N1 y N2 no resuelven puede estar regulado por otra norma ajena al sistema. Por ejemplo, Alchourrón y Bulygin muestran que los artículos 2777 y 2778 del antiguo Código Civil argentino no regulaban ciertos casos elementales del universo de casos relevante respecto de la restitución de un bien inmueble, pero ańaden que esto no es lo mismo que decir: ${ }^{40}$

... que el Código Civil Argentino tiene lagunas con respecto al problema de la reivindicación de los inmuebles contra terceros poseedores... Es muy posible que si el sistema S4 se integrará con alguna otra norma (por ejemplo, con alguna otra disposición del Código), las lagunas desaparecerían.

Por ejemplo, luego de la reforma de 1968 del antiguo Código Civil Argentino, el artículo 1051 protegía a los poseedores de buena fe a título oneroso y, por consiguiente, ofrecía una solución a algunas de las lagunas del ejemplo analizado por Alchourrón y Bulygin. El sistema formado por los artículos 2777, 2778 y 1051 no tiene una laguna en el caso de un actual poseedor de buena fe a título oneroso, con independencia de que hubiese recibido el inmueble de un enajenante de buena fe o de mala fe (casos $1 \mathrm{y}$ 2 del ejemplo de Alchourrón y Bulygin $)^{41}$.

La moraleja de este ejemplo es que una laguna no está necesariamente conectada con la discrecionalidad judicial ni con la creación discrecional de derecho ya que nada impide que en otro sector del ordenamiento exista una solución a la controversia. En ese caso, la modificación del sistema no es una prueba de creación de derecho porque la 'nueva' norma ya era jurídicamente válida, pero no había sido tenida en cuenta ${ }^{42}$.

\section{LA CONCEPCIÓN VALORATIVA DE LAS LAGUNAS NORMATIVAS}

Anteriormente he mencionado que la principal intuición subyacente a la concepción valorativa es que las lagunas normativas son 'algo más' que casos que el derecho no ha regulado y que ese elemento adicional no depende de la existencia de hechos sociales, sino de nuestra valoración de esos hechos. Una importante contribución a estas

40. Alchourrón, Carlos y Bulygin, Eugenio, 1974, p. 47.

41. Alchourrón, Carlos y Bulygin, Eugenio, 1974, p. 46.

42. En ciertas ocasiones, la norma que resuelve el caso y no forma parte del sistema emana de una fuente social que los jueces están autorizados a utilizar, pero que no son obligatorias. Al respecto, véase, GARDNER, 1988, pp. $457-461$. 
concepciones valorativas es la que ha ofrecido Juan Ruiz Manero en un trabajo publicado hace ya más de una década. No puedo hacer justicia aquí a la sutileza con que el profesor de Alicante defiende sus argumentos principales. Más bien, me limitaré a exponer brevemente cinco claves de su reconstrucción con el propósito de suministrar un contexto básico a su propuesta.

En primer lugar, Ruiz Manero sostiene que el derecho incluye no solo normas o reglas expresamente formuladas (y sus consecuencias lógicas) sino también las razones subyacentes a ese material normativo. Por razones de simplicidad, esas razones subyacentes serán denominadas 'principios' y asumiré que ellos ofrecen pautas morales apropiadas para justificar las normas del sistema jurídico. Las normas y los principios suministran el material normativo relevante para la justificación de la decisión de un determinado caso, pero ellos, por sí mismos, solo suministran soluciones provisorias o prima facie, mientras que las calificaciones concluyentes o definitivas surgen del balance de todos esos elementos normativos relevantes.

En segundo lugar, tanto las normas formuladas (y sus consecuencias lógicas) como los principios son soluciones jurídicas provisorias por diferentes razones. Mientras que los últimos, por su propia naturaleza abierta, tienen una dimensión de peso que solo cristalizan en respuestas concluyentes a la luz de un balance de principios, las normas son respuestas provisorias porque su alcance está abierto a una permanente revisión interpretativa, que refleja el peso de los diferentes principios relevantes en un determinado caso

En tercer lugar, la calificación provisoria que ofrece un principio se 'transforma en deber concluyente siempre que, en relación con las propiedades del caso, no concurra otro principio que tenga, en relación con esas mismas propiedades, un mayor peso ${ }^{43}$. A su vez, la calificación prima facie de una norma (e.g., una norma de obligación) se transforma en concluyente cuando no hay una razón de principio para modificar el deber que ella impone. Por tanto, no se pueden identificar las calificaciones concluyentes de las normas sin previamente determinar la fuerza concluyente de los principios subyacentes.

En cuarto lugar, la calificación concluyente de una norma no depende del hecho de que ella sea utilizada como razón operativa del razonamiento justificatorio. Cualquier norma puede ser mal aplicada cuando, a la luz del balance de razones, se le atribuye una fuerza concluyente que no posee. Por la misma razón, el peso concluyente de los principios en conflicto no puede ser determinado por el papel que de hecho juegan en el razonamiento práctico del juez, sino más bien esos argumentos serán correctos o incorrectos en la medida en que exista un criterio independiente de asignación de fuerza a cada principio. En este sentido, los jueces descubren, mediante el balance de

43. Ruiz Manero, 2005, p. 121.

Doxa. Cuadernos de Filosofía del Derecho, (2020), 43, pp. 159-187 
razones, la respuesta correcta que el derecho impone como premisa operativa de su razonamiento justificatorio ${ }^{44}$.

En quinto lugar, esta reconstrucción objetiva del balance de principios permitiría dar cuenta de que en casos de lagunas, las discrepancias entre juristas no son una polémica acerca de la mejor reforma posible de un cierto sistema (discrepancias acerca de cómo debería ser el derecho), sino un genuino desacuerdo acerca de las calificaciones concluyentes que el derecho ofrece para ciertos $\operatorname{casos}^{45}$. De igual modo, las decisiones judiciales en casos de lagunas no son necesariamente discrecionales sino guiadas por el balance de razones subyacentes.

Estos elementos son suficientes para comprender la propuesta de Ruiz Manero ${ }^{46}$ :

Un cierto caso constituye una laguna normativa de un cierto sistema jurídico si y solo si (1) ese sistema jurídico no contiene una regla que correlacione el caso con una solución normativa y (2) el balance entre los principios relevantes de ese sistema jurídico exige una regla que correlacione el caso con una solución normativa que califique la conducta de que se trate como obligatoria o prohibida.

En virtud de que la primera cláusula del concepto de Ruiz Manero es sustancialmente idéntica a la definición de Alchourrón y Bulygin, mi análisis se referirá exclusivamente a las diferencias que se producen por la aplicación de la segunda condición de la reformulación de Ruiz Manero y, a efectos de preservar la homogeneidad de la comparación, asumiré que los dos enfoques están exclusivamente interesados en las calificaciones concluyentes. Mis críticas se centrarán en dos cuestiones relacionadas: (a) la irrelevancia de las reglas permisivas, y (b) las relaciones entre principios y normas.

\section{a) Irrelevancia de las reglas permisivas}

La reconstrucción de Ruiz Manero es una visión más bien escéptica de la función normativa independiente de las normas permisivas. Conforme a la primera cláusula, un caso solucionado con una norma permisiva no es una laguna $y$, de acuerdo con la segunda cláusula, tampoco es una laguna un caso que carece de solución cuando el balance de principios se decanta por una regla permisiva. En otras palabras, las normas permisivas, por sí mismas, son más bien irrelevantes ya que su presencia o ausencia no incide en la existencia de lagunas.

Ruiz Manero no proporciona ejemplos de lagunas normativas y, por consiguiente, no hay evidencia textual explícita del modo en que su enfoque reconstruye la práctica jurídica. Por esta razón, es útil retomar el conocido ejemplo de Alchourrón y Bulygin acerca del modo en que el viejo Código Civil Argentino de Vélez Sarsfield resuelve el

44. Acerca de estas dificultades, véanse las importantes observaciones de Alchourrón y Bulygin acerca de los 'Paradigmas realistas y conceptualistas' en Alchourrón y Bulygin, 1991, pp. 600-609.

45. Ruiz Manero, 2005, pp. 111-112.

46. Ruiz Manero, 2005, p. 123. 
problema de la restitución de bienes inmuebles. Como he señalado anteriormente, los artículos formulados por Vélez Sarsfield para esta cuestión son el 2777 y 2778 , que se refieren a diferentes situaciones que surgen de la combinación de tres propiedades: buena fe del enajenante, buena fe del adquirente y título oneroso.

Esos artículos expresan las siguientes normas:

N1: OR/ $\neg$ BFE\&BFA\&TO (Es obligatorio restituir en caso de mala fe del enajenante, buena fe del adquirente y título oneroso.)

N2: OR/ᄀTO (Es obligatorio restituir en caso de transferencia a título gratuito.)

La matriz de este sistema se muestra en el siguiente diagrama:

\begin{tabular}{|c|c|c|c|c|c|}
\hline & BFE & BFA & TO & N1 & N2 \\
\hline $\mathbf{1}$ & + & + & + & & \\
\hline $\mathbf{2}$ & $\neg$ & + & + & OR & \\
\hline $\mathbf{3}$ & + & $\neg$ & + & & \\
\hline $\mathbf{4}$ & $\neg$ & $\neg$ & + & & \\
\hline $\mathbf{5}$ & + & + & $\neg$ & & OR \\
\hline $\mathbf{6}$ & $\neg$ & + & $\neg$ & & OR \\
\hline 7 & + & $\neg$ & $\neg$ & & OR \\
\hline $\mathbf{8}$ & $\neg$ & $\neg$ & $\neg$ & & OR \\
\hline
\end{tabular}

Alchourrón y Bulygin señalan que los casos 3 y 4 son lagunas, aun cuando esas situaciones no fueron consideradas problemáticas por la dogmática argentina. Probablemente, la explicación más plausible de ese desinterés es el consenso acerca de la obligatoriedad de restituir el inmueble en los casos 3 y 4 , aun cuando no haya una solución explícita ni implícita para ellos en este sistema. Ese consenso surge de un argumento de principio: la buena fe merece una especial protección y, por consiguiente, un caso de buena fe no puede encontrarse en peor posición que uno de mala fe ${ }^{47}$. Dado que en el caso 2 el actual poseedor de buena fe a título oneroso está obligado a restituir el inmueble, con mayor razón debe hacerlo el adquirente de mala fe (casos 3 y 4). Sin embargo, la solución de los casos 3 y 4 también podría haberse obtenido mediante un argumento a contrario sensu a partir de los casos 7 y 8 , dando primacía a la naturaleza onerosa de la transferencia. Si las diferencias entre los pares de casos (3-7) y (4-8) es exclusivamente la presencia o ausencia de título oneroso, podría argumentarse de la siguiente manera: si en caso de transferencias a título gratuito es obligatoria la restitución (casos 7 y 8), entonces en casos en que la transferencia fuese a título oneroso, la restitución no es obligatoria (casos 3 y 4). En este argumento, el principio subyacente sería el de la mejor posición de los actos onerosos frente a los actos a título gratuito. Conforme a esta hipotética solución, el balance de principios hubiese resultado en la exigencia de una regla que protegiese normativamente la situación del actual poseedor a título

47. Alchourrón, Carlos y Bulygin, Eugenio, 1974, p. 48. 
oneroso. Sin embargo, a diferencia de lo que ocurre en la concepción de Alchourrón y Bulygin, Ruiz Manero hubiese descartado que esa situación ejemplifique una genuina laguna normativa ya que, en su opinión, carece de mayor relevancia la permisión de conductas que no están prohibidas. Esta conclusión se manifiesta con mayor intensidad en el análisis del caso 1.

El caso 1 carece de solución y esa laguna normativa fue la que motivó un importante debate en la dogmática argentina acerca del mejor modo de resolver esa indeterminación. Esta es la conclusión que defienden Alchourrón y Bulygin pero, por el contrario, Ruiz Manero no admite que ese caso represente una 'genuina' laguna ya que no satisface la segunda cláusula de su reconstrucción. A diferencia de lo que ocurre con el balance de razones en los casos 3 y 4 , en el caso 1 no parece tener mucho sentido extraer una regla de obligación del balance de razones subyacentes. Si se impusiese una obligación de restituir para el caso 1, todas las propiedades se convertirían en irrelevantes ya que todos los restantes casos están correlacionados con la misma solución ${ }^{48}$. Por tanto, la autorización (facultad) de restituir el inmueble es la opción más razonable para la solución de este caso ya que preserva la relevancia de las tres propiedades del universo de propiedades relevantes en caso de un actual poseedor de buena fe y a título oneroso, que hubiese recibido el bien de un enajenante de buena fe.

¿Por qué rechaza Ruiz Manero que el caso 1 sea una genuina laguna normativa? Las razones se conectan intrínsecamente con la equivalencia pragmática que existe entre permitir una conducta y simplemente no prohibirla ${ }^{49}$. Aquellas situaciones en las que solo tiene sentido dictar normas permisivas (e.g., caso 1) serían pragmáticamente equivalentes a situaciones en las que no hay razones concluyentes para regular un comportamiento y estas situaciones, a su vez, serían ejemplos de casos irrelevantes. En otras palabras, Ruiz Manero asimilaría la laguna del caso 1 con los conflictos que, por ejemplo, podrían producirse en situaciones como el de una pareja que no se pone de acuerdo en el lugar donde pasar sus vacaciones. En su opinión ${ }^{50}$ :

De acuerdo con la definición, pues, en relación con el caso de las vacaciones matrimoniales el sistema jurídico no contendría laguna alguna. La razón es que, de acuerdo con los principios que informan la institución matrimonial en los sistemas jurídicos que reconocen la igualdad entre los sexos, una eventual regla referida a este caso no podría ser sino permisiva... Y este mismo efecto -el hecho de que plegarse, o no plegarse, a los deseos del otro cónyuge sea una conducta disponible, es decir, libre de restricciones normativas, para cada uno de ellos- viene determinado igualmente por la ausencia de una regla al respecto.

A la luz de los principios subyacentes al régimen matrimonial de un derecho liberal, ese conflicto de intereses entre los cónyuges es un caso irrelevante porque hay buenas

48. El caso 2 es expresamente resuelto como obligatorio por la norma N1, para los casos 5 a 8 se derivan, como consecuencia lógica de $\mathrm{N} 2$, la obligatoriedad de la restitución y la misma solución se obtenía para 3 y 4 como resultado del balance de principios subyacentes.

49. Véase Atienza y Ruiz Manero, 1996, pp. 92-96. También, véase Ross, 1968, p. 122 y Lewis, 1979, pp. 163-174.

50. Ruiz Manero, 2005, p. 124. 
razones para dejar esa situación sin regular. Sin embargo, en el marco del ejemplo de la restitución de bienes inmuebles (el caso 1), la situación es distinta. La diferencia básica es la siguiente: el conflicto de intereses de los cónyuges acerca del caso de las vacaciones es una acción que no está específicamente regulada en ninguna circunstancia y por ello es que puede mencionarse como un ejemplo de aquello 'que el derecho no regula ni pretende regular'. Es decir, no tiene mucho sentido pensar que la disponibilidad de esa acción depende de una combinación específica de propiedades (universo de propiedades) que ha sido insuficientemente resuelta por el legislador. Por el contrario, en el caso 1 del ejemplo de Vélez Sarsfield, la acción en cuestión (i.e., la restitución de bienes) es regulada en numerosos sectores del ordenamiento jurídico y en especial en diversos casos del universo de casos relevantes que el legislador ha diseñado para enfrentar al problema de la reivindicación de bienes inmuebles. Por ello, no hay mayores razones para sostener que se trata de una acción que el 'derecho no regula ni pretende regular'.

En resumen: parece natural asumir que, en casos de lagunas, el balance no solo impone obligaciones o prohibiciones, sino también reconoce una determinada facul$\operatorname{tad}^{51}$, limitando las opciones discrecionales de los jueces ${ }^{52}$. Esta es una modificación relativamente menor para la reconstrucción de Ruiz Manero y sería perfectamente asumible en su esquema conceptual.

\section{b) Relaciones entre principios y normas}

El inagotable debate acerca de las normas y principios jurídicos refleja diferentes concepciones acerca del contenido del derecho y, en particular, con frecuencia gira en torno a la validez de las pautas implícitas que se pueden extraer del material normativo expresamente formulado por las autoridades. En la teoría del derecho tradicional, los principios jurídicos desempeñan un papel normativo subordinado; algo así como un recurso retórico para justificar la incorporación o eliminación de normas. Para estas teorías, las normas son las pautas de motivación más importantes y los principios ocupan un lugar residual para casos de indeterminación en los que las normas no ofrecen soluciones completas y coherentes. Esta primacía de las normas expresa ciertos valores sustantivos inherentes al modelo clásico del Estado de Derecho y no es posible abordar aquí los detalles y desafíos de este diseño institucional ${ }^{53}$. Para ilustrar esta dependencia de los principios frente a las normas puede mencionarse al artículo 11 de la Ley de Contrato de Trabajo de Argentina (13/5/1976), que establece:

Cuando una cuestión no pueda resolverse por aplicación de las normas que rigen el contrato de trabajo o por las leyes análogas, se decidirá conforme a los principios de la justicia social, a los generales del derecho del trabajo, la equidad y la buena fe.

51. Para una crítica similar, véase, Bayón, 2009, p. 58, nota 29. También, en ATienza, 2009, pp. 111-112.

52. Por ejemplo, véase el trabajo de Alonso, 1995, pp. 403-431, donde se analiza el caso de la compensación de los gastos útiles de mala fe cuando el poseedor vencido reclama el reconocimiento de esas erogaciones.

53. Para un análisis contemporáneo de la conexión entre reglas y Estado de Derecho, véase, LAPORTA, 2007. 
Sin embargo, en la teoría contemporánea es usual asumir que los principios ocupan una posición diferente ya que no solo sirven como un suplemento que opera de manera subsidiaria a las normas formuladas por la autoridad, sino que también tienen directa relevancia normativa ya que ofrecen pautas de justificación que pueden revisar y desplazar las calificaciones que se obtienen de las normas. Los principios generan nuevas reglas en tanto que justifican soluciones diferentes a las expresamente suministradas por las normas formuladas. Pero, la validez de esas nuevas reglas no depende de su efectivo reconocimiento por parte de jueces o autoridades, sino del peso que objetivamente tienen los principios jurídicos en cada ocasión concreta de aplicación.

Estas dos concepciones sitúan a los principios en diferentes espacios del ordenamiento jurídico. Mientras que la primera concepción reconoce a los principios como 'fuentes del derecho', apropiados para resolver aquellas situaciones que las normas no han regulado, la segunda concepción los integra como parte vinculante del derecho. En la primera concepción, una laguna puede ser solucionada usando un principio para modelar una nueva norma general y la validez de esa nueva norma dependerá de la autoridad que la formule, pero en la segunda concepción, los principios ofrecen, por sí mismos, una solución a la controversia, aunque su peso específico en ese conflicto dependerá del balance entre principios en conflicto.

Ruiz Manero asume esta segunda concepción de los principios. Según el profesor de Alicante: ${ }^{54}$

El resultado de este balance de principios concurrentes es una regla que establece la prevalencia de uno de ellos, dadas ciertas circunstancias genéricas, esto es, el deber concluyente de realizar, dadas tales circunstancias, la conducta prescrita en el consecuente de uno de ellos.

Por consiguiente, el resultado del balance es una regla que califica conductas y no una 'meta-regla' que simplemente justifica la introducción de otra regla que califique conductas. Más bien, la idea de Ruiz Manero parece ser similar a la expuesta por Alexy: el resultado del balance de principios es una regla conceptual que define la jerarquía entre principios para un determinado universo de casos y esas condiciones de precedencia entre principios constituyen el supuesto de hecho de una regla que impone las consecuencias jurídicas del principio superior ${ }^{55}$.

En segundo lugar, las reglas que surgen del balance de principios serán parte del derecho en la misma medida en que los principios son parte del derecho ${ }^{56}$. En otras palabras, esas reglas están implícitas en el derecho de esa comunidad. Si se admite que los principios son pautas jurídicamente vinculantes, entonces no hay razones para negar la validez de las reglas resultantes del balance de principios jurídicos.

54. Ruiz Manero, 2005, p. 121.

55. Alexy, 1993, pp. 90-95.

56. Los principios no satisfacen necesariamente las relaciones sistemáticas clásicas de legalidad o deducibilidad. Sin embargo, en la medida en que los principios justifican la revisión interpretativa de las normas formuladas (I.e., afectan su significado), ellos están internamente relacionados con el material expresamente promulgado y forman parte del mismo sistema jurídico. Véase, RAZ, 1970, p. 24. 
En tercer lugar, como he señalado anteriormente, para Ruiz Manero los juristas discrepan acerca de las calificaciones concluyentes que surgen del balance de principios y esa controversia no es acerca de aquello que debe ser el derecho sino acerca de lo que verdaderamente exige el derecho. Aquello que concluyentemente exige el derecho no depende de las preferencias de los juristas o de las decisiones de los jueces sino del correcto balance de los principios subyacentes. Dado que el balance es 'objetivo', el contenido del derecho está implícito en el conglomerado de reglas y principios y los jueces tienen que descubrir la respuesta correcta (el balance apropiado) para cualquier circunstancia. Esta respuesta, que juristas y jueces tienen que descubrir en el material jurídico, será una obligación jurídicamente concluyente o una permisión jurídicamente concluyente que ya forman parte del derecho.

En resumen, antes de realizar el balance de principios subyacentes no podemos determinar si un cierto caso es una genuina laguna normativa o un caso irrelevante. Pero, si después del balance de principios se descubre una regla válida que impone una obligación, entonces el caso en cuestión no era una laguna porque que el sistema ya contenía una regla que solucionaba la controversia. Por el contrario, si después del balance de principios no se identifica a una regla válida que impone una cierta obligación, entonces el caso en cuestión no era una laguna ya que no satisface la segunda cláusula de la reconstrucción de Ruiz Manero. En resumen: antes del balance de principios no es posible determinar si un caso es una genuina laguna normativa o un caso irrelevante y después del balance de principios tampoco es posible identificar ese tipo de lagunas. Más allá de otras innegables virtudes que tiene el enfoque de Ruiz Manero, no parece de gran utilidad un concepto de laguna que no permita identificar en la práctica a esas indeterminaciones.

\section{LOS CASOS IRRELEVANTES COMO PROBLEMAS EXTERNOS AL DERECHO}

En las secciones anteriores he mostrado que las concepciones objetiva y evaluativa proporcionan respuestas inadecuadas al problema de la distinción entre lagunas y casos irrelevantes. Por esa razón, las conexiones entre los casos que el derecho no regula y la creación discrecional de derecho por parte de los jueces también está caracterizada de manera imprecisa. En esta sección señalaré que un avance en la solución de este problema exige una clara distinción entre acciones y casos. Por extraño que parezca, los críticos al modelo clásico de Alchourrón y Bulygin no han prestado mayor atención a esta distinción. Por ejemplo, Carlos Nino señala ${ }^{57}$ :

... ningún jurista llamaría incompleto a un orden jurídico que no regula, por ejemplo, la acción de mover el dedo meńique o tartamudear... El concepto central de laguna es de

57. Por ejemplo, Nino, 1979, Reimpreso en el 1995. Véase, la página 72 de esta última edición. También, MaZZARESe, 2002, p. 138. 
índole valorativa: un sistema tiene una laguna cuando no contiene ninguna solución normativa para un cierto caso, a pesar de que debería contener una solución.

Mientras que la primera parte del argumento de Nino se refiere a acciones irrelevantes, la segunda parte conecta con propiedades (casos) irrelevantes. En el mismo sentido, Bayón afirma ${ }^{58}$ :

...se tiende a presuponer que solo cabe hablar con propiedad de laguna cuando no esté regulado un caso que derecho 'pretende' o 'tendría que' regular (de otro modo, y salvo que el sistema contenga una norma de clausura que haga posible que toda acción imaginable quede calificada deónticamente, el número de 'lagunas' resultaría literalmente ilimitado: esto es, todo sistema no cerrado o clausurado tendría un número infinito de lagunas) (Itálicas ańadidas)

En una concepción del derecho que admite que los sistemas jurídicos incluyen todas sus consecuencias lógicas, la distinción entre casos y acciones es importante ya que mientras que las calificaciones normativas se proyectan desde los casos menos finos hacia los casos más finos, en el universo de acciones la relación se obtiene en sentido inverso. Por ello, en un sistema completo, el ańadido de un infinito conjunto de propiedades $\mathrm{P}$ a un cierto universo de casos relevantes implica que los elementos de P son normativamente irrelevantes siempre que el sistema mantenga su coherencia. Pero nada similar ocurre con los elementos del universo de acciones. En este caso, como se señaló anteriormente, las soluciones se heredan desde conjuntos más finos hacia los menos finos. Por ello, de la relevancia de una propiedad respecto de un determinado universo de acciones nada puede inferirse acerca de su relevancia con relación a otra acción (i.e., otro problema) diferente. La inadvertencia de este rasgo de la relevancia normativa explica la crítica de Ruiz Manero a Alchourrón y Bulygin. En su opinión, la acción de beber zumo de naranja en el desayuno de un día de marzo antes de las 8 de la mañana es irrelevante para el derecho y, por consiguiente, no es un ejemplo de laguna normativa. Para que una cierta situación sea una laguna es preciso que se trate de un caso relevante y, en opinión de Ruiz Manero ${ }^{59}$,

... aquí es donde el modelo de Alchourrón y Bulygin ofrece una respuesta que no acaba de resultar satisfactoria: de acuerdo con ellos, sería relevante todo caso en el que estuviera presente que alguna regla jurídica considerara como relevante. Y aquí nos bastaría introducir una pequeña modificación en el caso anterior para transformarlo en jurídicamente relevante (de acuerdo con el criterio de relevancia postulado por Alchourrón y Bulygin); añadiendo a las propiedades de que se trate de un desayuno en un día de marzo y antes de las 8 de la mañana, la propiedad de que las personas que participan en él estén casadas entre sí (pues la propiedad de estar casado es una propiedad que numerosas reglas jurídica que no regulan, desde luego, la acción de desayunar, sino otras acciones ciertamente muy distintas, consideran como relevante). Y resulta intuitivamente claro que la presencia de la propiedad de estar casados quienes desayunan no añade ni un ápice de relevancia al

58. BAYÓN, 2009, p. 33.

59. Ruiz Manero, 2015, p. 49.

Doxa. Cuadernos de Filosofía del Derecho, (2020), 43, pp. 159-187 
caso en cuestión, que nos parece con claridad que sigue siendo perfectamente irrelevante para el derecho.

Esta crítica atribuye errores que no presenta el modelo de Alchourrón y Bulygin. En particular, aunque la propiedad 'estar casado' es relevante para muchos problemas normativos, e.g., régimen patrimonial, acceso a subsidios, etc., esto no significa que esa propiedad es irrelevante respecto de cualquier universo de acciones. De este modo, si una acción (e.g., beber zumo de naranja) no está deónticamente determinada en relación con ninguna propiedad, entonces puede ocurrir que el añadido de otra propiedad relevante para otra acción (e.g., régimen patrimonial) carezca de impacto normativo. Eso es lo que permite concluir a Ruiz Manero que la propiedad de 'estar casado' no añade ni un ápice de relevancia al problema del desayunar zumo a las 8 de la mañana de un día de marzo. Esta es la conclusión que se obtiene del enfoque de Alchourrón y Bulygin y la confusión de Ruiz Manero surge de asumir que para ellos si una propiedad es jurídicamente relevante para un problema conserva esa relevancia en cualquier otro problema diferente.

A efectos de evitar estas confusiones adaptaré las definiciones de relevancia de propiedades y acciones introducidas por Alchourrón y Bulygin ${ }^{60}$, diré que una acción $\mathrm{R}$ es relevante cuando está normativamente determinada, i.e. $\mathrm{R}$ es calificada como obligatoria, prohibida o permitida. Cuando un caso $\mathrm{C}_{\mathrm{i}}$ es identificado como una laguna normativa, el micro-sistema que se utiliza para regular una cierta acción $\mathrm{R}$ ofrece una solución para $\mathrm{R}$ respecto de ciertos casos, aunque el caso elemental $\mathrm{C}_{\mathrm{i}}$ en cuestión no tenga correlacionada una solución. En este sentido, la acción $\mathrm{R}$ es relevante ya que aun cuando las lagunas son casos sin regular, $\mathrm{R}$ está normativamente determinada por el sistema normativo en otros casos del universo de casos. Por el contrario, una acción pertenece a la esfera extranormativa cuando es irrelevante en el ordenamiento jurídico (o macro-sistema, o sistema total). Es decir, una acción es irrelevante cuando cualquier propiedad $\mathrm{p}_{1}, \mathrm{p}_{2}, \ldots, \mathrm{p}_{\mathrm{n}}$ es irrelevante respecto de esa acción específica. En este sentido, si una acción está ubicada en la esfera extranormativa, entonces no hay ningún subsistema del ordenamiento jurídico que regule esa conducta y ninguna propiedad es relevante en el derecho de esa comunidad para determinar su estatus deóntico con relación a ningún caso.

Dado que las propiedades son relevantes con relación a una determinada acción, la identificación del universo de casos relevantes UCR supone que previamente se ha determinado un cierto Universo de Acciones UA que fija el problema normativo. Una modificación en la amplitud del universo de acciones significa un cambio de problema normativo y nada asegura que el sistema útil para resolver un cierto problema A también sea apropiado para resolver otro problema B. Por ello, a diferencia de las lagunas normativas -que son problemas internos a un micro-sistema que regula una determinada acción- los 'casos irrelevantes' son problemas externos a los sistemas normativos y se refieren a la calificación normativa de acciones que están más allá

60. Alchourrón y Bulygin, 1974, p. 153. 
de las conductas reguladas por las normas positivas. En este sentido, no se trata de que esa acción sea irrelevante para un determinado sector del ordenamiento como el derecho agrario, o el derecho de la Comunidad Autónoma de Valencia, sino que esa conducta es indiferente respecto del contenido explícito o implícito de cualquier otra norma del ordenamiento.

Esta reconstrucción, sin embargo, no es unánimemente aceptada. Por ejemplo, Atienza y Ruiz Manero distinguen entre casos en la esfera extranormativa (que denominan 'indiferencia') y otros casos en los que una conducta relevante para un sistema $S$ carece de solución, pero señalan que ${ }^{61}$ :

... parece obvio que hay formas de conducta en las que el Derecho de Familia, o el Derecho de la Comunidad Autónoma de Valencia, no están interesado. En relación con el sistema jurídico en su conjunto cabe dudar, sin embargo, de que haya conductas propiamente indiferentes. El hecho de que, como dice Raz..., los sistemas jurídicos pretendan autoridad para regular cualquier conducta - esto es, reclamen para sí una competencia material ilimitada- es un buen argumento en favor de la tesis de la inexistencia (desde el punto de vista del sistema jurídico en su conjunto) de conductas indiferentes: aquí cabría decir que - en virtud de la competencia material ilimitada que los sistemas jurídicos reclaman para sí- todo lo no prohibido está permitido, esto es regulado jurídicamente.

Con independencia de la plausibilidad de la distinción entre la esfera normativa y las lagunas, el argumento de Atienza y Ruiz Manero acerca del ámbito de indiferencia no es persuasivo. En el párrafo reproducido arriba hay tres ideas diferentes. En primer lugar, el alcance restringido de la esfera de indiferencia; en segundo lugar, las dudas acerca de si existen conductas indiferentes en el sistema jurídico en su conjunto y, finalmente, la referencia a Raz como apoyo para concluir que todo lo no prohibido está permitido, esto es, regulado jurídicamente. Dejaré de lado por el momento la discusión acerca de la primera idea y me concentrar en las dos últimas.

Atienza y Ruiz Manero utilizan el argumento de Raz acerca de la naturaleza comprehensiva de los sistemas jurídicos como fundamento de su última tesis, referida a la inexistencia de conductas jurídicas indiferentes en el sistema global, y de la verdad de la afirmación de que todo lo que no está prohibido está regulado (permitido) en ese ordenamiento. Sin embargo, es necesario destacar que cuando Raz señala que los sistemas son comprehensivos solo intenta señalar que ellos pretenden tener autoridad para regular cualquier conducta ${ }^{62}$, pero de allí no se sigue que, de hecho, los sistemas jurídicos efectivamente hayan regulado toda acción posible. Más bien, Raz niega que las conductas débilmente permitidas estén regulas por el derecho. En su opinión ${ }^{63}$,

61. Atienza y Ruiz Manero, 1996, p. 106.

62. Raz, 1979, p. 116. Este párrafo es reproducido en RAZ, 1990, p. 150, que es el texto al que se refieren Atienza y Ruiz Manero.

63. Raz, 1979, p. 117.

Doxa. Cuadernos de Filosofía del Derecho, (2020), 43, pp. 159-187 
Un sistema normativo, sin embargo, no regula la conducta meramente permitida en sentido débil. Un acto está débilmente permitido si el sistema no contiene una norma que lo prohíba. Está permitida en sentido fuerte si el sistema contiene una norma que la permite.

Esta afirmación parece incompatible con la tesis de Raz según la cual el derecho carece de lagunas y tal vez esa sea la razón por la que Atienza y Ruiz Manero invocan a Raz en apoyo de su intuición sobre la exhaustividad del derecho en su conjunto. No abordaré aquí esta cuestión ${ }^{64}$. Solo señalaré que cuando Raz sostiene que no hay lagunas no pretende negar que existan casos que el derecho no regula (i.e., permite débilmente), sino más bien su respuesta evoca la posición de Kelsen: los jueces siempre disponen de una justificación (en términos de 'permitido' o 'prohibido' concluyentemente) frente a cualquier situación dentro de su ámbito de competencia ${ }^{65}$. De esta manera, aunque el derecho no regule todas las acciones, esas conductas débilmente permitidas están protegidas ya que ellas están concluyentemente permitidas cuando no hay razones concluyentes para que el juez disponga su omisión.

En conclusión, la teoría de Raz no ofrece respaldo para el enfoque de Atienza y Ruiz Manero acerca de la inexistencia de conductas indiferentes en el sistema jurídico en su conjunto (en el 'ordenamiento jurídico'). La moraleja a extraer de este análisis es que es necesario distinguir claramente entre las lagunas normativas, que son indeterminaciones internas a un micro-sistema normativo, y los casos irrelevantes, que son problemas externos al ordenamiento jurídico. En este sentido, los casos irrelevantes pertenecen a una esfera extranormativa que 'escapa' a todas las normas válidas de la comunidad (i.e., al ordenamiento jurídico) y no solamente a un sector específico (e.g., el derecho civil) del derecho. El contenido intuitivo de los ejemplos de 'casos irrelevantes' invocados por los críticos de la concepción objetiva (e.g., escoger el color de los pantalones, mover el dedo meñique, hablar por teléfono con los amigos, escoger un sitio de vacaciones, etc. ${ }^{66}$ ) conlleva el mensaje de que esas situaciones son tan intrascendentes para la vida social que ninguna norma jurídica se refiere a ellas. Por el contrario, la existencia de una laguna en un micro-sistema normativo (i) presupone que la acción en cuestión está regulada en un cierto conjunto de circunstancias, aunque desafortunadamente uno o varios casos de esa combinación carezcan de solución y (ii) es compatible con el hecho de que otro subsistema del ordenamiento (i.e., del conjunto de normas válidas) ofrezca una solución. En definitiva, mientras que en casos de lagunas normativas las acciones pertenecen al conjunto de acciones reguladas (al menos, en algún otro caso diferente al que ejemplifica la laguna), las acciones que pertenecen a la esfera extranormativa no son reguladas por ninguna norma del ordenamiento. El

64. Raz niega que existan lagunas cuando 'el derecho guarda silencio', pero enfatiza que otros tipos de indeterminaciones normativas surgen cuando 'el derecho habla con voz incierta', I.e., en casos de vaguedad o conflictos de razones jurídicas. Véase, RAz, 1979, pp. 73-80.

65. Raz, 1979, p.71.

66. Estos ejemplos son los que mencionan Atienza y Ruiz Manero, Carlos Nino, Tecla Mazzarese y Fernando Atria, respectivamente. Tanto la lista de acciones irrelevantes como de autores preocupados en distinguirlas de las lagunas normativas podría ser fácilmente expandida. 
ordenamiento jurídico no las regula ni pretende regularlas y, en ese sentido, están más allá de los límites del derecho.

\section{CONCLUSIONES}

Las principales ideas que he defendido en este trabajo pueden resumirse en las siguientes afirmaciones:

- Los sistemas jurídicos son sistemas normativos abiertos. Como consecuencia de esa peculiar naturaleza, es preciso rechazar que ellos necesariamente regulen a cualquier situación posible.

- Aunque el derecho no regule una determinada esfera de conducta, no es necesario asumir que un conflicto de intereses acerca de esa situación requiera una decisión discrecional por parte de los jueces. Por ejemplo, es frecuente que el derecho deje sin regular ciertas esferas de conducta para que los individuos puedan desarrollar planes de vida y asumir compromisos normativos en ese ámbito de libertad. En virtud de su naturaleza abierta, el derecho protege y da valor -sin incorporarlos como parte del sistema jurídico- a los acuerdos privados que los individuos desarrollan en el marco de su autonomía.

- Otras situaciones que el derecho no regula (ni pretende regular) son casos irrelevantes, que parecen escapar del ámbito jurídico por su escasa relevancia social (e.g. mover un dedo). La teoría jurídica tradicional ha señalado que las lagunas normativas son 'algo más' que casos irrelevantes porque son situaciones que el derecho debería regular.

- La teoría tradicional también destaca que en casos irrelevantes, los jueces carecen de discrecionalidad y que una exigencia relativa a un caso irrelevante debe ser rechazada. Sin embargo, en caso de lagunas, los jueces podrían crear intersticialmente derecho.

- Para trazar una adecuada delimitación entre lagunas y casos irrelevantes es preciso distinguir entre (i) micro-sistemas y ordenamiento jurídico y (ii) acciones y propiedades relevantes.

- La separación entre casos de lagunas y otros casos irrelevantes que el derecho no regula ni pretende regular no requiere un argumento evaluativo. Mientras que en casos de lagunas, la acción en cuestión carece de regulación en un cierto caso (pero tiene solución en otras circunstancias) por parte del micro-sistema, los 'casos irrelevantes' son simplemente acciones que no están deónticamente determinadas en el ordenamiento jurídico (sistema total).

Finalmente, un análisis completo de los casos irrelevantes tiene que enfrentar el problema de la eventual discrecionalidad que los jueces tendrían en caso de que surgiese un conflicto de intereses acerca de una conducta en la esfera extranormativa. Bulygin traza una distinción en los casos de esta esfera entre aquellas situaciones que el juez 
encuentra carente de interés y otros casos que impresionan al juez como suficientemente serios ${ }^{67}$. En este último supuesto, Bulygin afirma que el magistrado lo tratará de manera similar a una laguna normativa y ello significa que resolverá ese caso mediante la creación discrecional de una nueva norma. Por tanto, aunque los casos no regulados no son 'simplemente' lagunas normativas, el juez tiene discreción para clasificarlos como irrelevantes (y rechazar la demanda) o como lagunas (si es que lo considera suficientemente importantes y así crea nuevo derecho para resolver el conflicto). Esto significa que, para Bulygin, no hay límites normativos externos que controlen la clasificación que un juez realiza de un determinado conflicto irrelevante y, por consiguiente, su decisión de rechazar la demanda o de sustanciar el pleito de manera similar a los casos de lagunas, no es jurídicamente correcta ni incorrecta.

Por el contrario, una concepción evaluativa (e.g., la propuesta por Ruiz Manero) insistirá en que nuestros diseños institucionales niegan esa discrecionalidad judicial. Más bien, estas teorías insistirán en que la decisión judicial acerca de la irrelevancia de un caso -y su posterior desestimación- es una cuestión guiada por los principios del ordenamiento y que, por esta misma razón, la decisión de suministrar apoyo institucional en casos 'suficientemente serios' no es discrecional sino normativamente guiada por los principios del ordenamiento jurídico.

Aunque ambas teorías capturan importantes aspectos de nuestras prácticas jurídicas, una evaluación crítica de estas propuestas no puede abordarse en este trabajo.

\section{BIBLIOGRAFÍA}

Alchourrón, Carlos, 1991: 'Lógica de normas y lógicas de proposiciones normativas', en Alchourrón, Carlos y Bulygin, Eugenio, Análisis lógico y derecho, Madrid: Centro de Estudios Constitucionales, pp. 25-50

Alchourrón, Carlos y Bulygin, Eugenio: 1974, Introducción a la metodología de las ciencias jurídicas y sociales, Buenos Aires: Astrea

Alchourrón, Carlos y Bulygin, Eugenio: 1991, 'Permisiones y normas permisivas', en Alchourrón, Carlos y Bulygin, Eugenio, Análisis lógico y derecho, Madrid: Centro de Estudios Constitucionales, pp. 215-238,

Alchourrón, Carlos y Bulygin, Eugenio: 1991, 'Libertad y autoridad normativa', en Alchourrón, Carlos y Bulygin, Eugenio, Análisis lógico y derecho, Madrid: Centro de Estudios Constitucionales, pp. 219-248

Alchourrón, Carlos y Bulygin, Eugenio, 1991: 'Verdad deóntica y valores', en Alchourrón, Carlos y Bulygin, Eugenio, Análisis lógico y derecho, Madrid: Centro de Estudios Constitucionales, pp. 591-610

Alexy, Robert, 1993: Teoría de los derechos fundamentales (Trad. de Garzón Valdés, E. et al), Madrid, Centro de Estudios Constitucionales

Alonso, Juan Pablo, 1985: 'Un caso difícil en el código civil español', Doxa 17-18

67. Bulygin, 2005, p. 83. 
Atienza, Manuel y Ruiz Manero, Juan, 1996: Las piezas del derecho, pp. 92-96, Barcelona: Ariel

Atienza, Manuel, 2009: 'Sobre «creación judicial de derecho» de Eugenio Bulygin' en Bulygin, Eugenio et al, Problemas lógicos en la teoría y práctica del derecho, Madrid: Fundación Coloquio Jurídico Europeo, pp. 95-126

Atria, Fernando, 2005: 'Sobre las lagunas', en Atria, Fernando. et al, Lagunas en el derecho, Madrid: Marcial Pons, pp. 15-28

Atria, Fernando, 2005: 'Creación y aplicación del derecho: entre formalismo y escepticismo' en Atria, Fernando. et al, Lagunas en el derecho, Madrid: Marcial Pons, pp. 45-72

Bayón, Juan Carlos, 2009: 'Sobre el principio de prohibición y las condiciones de verdad de las proposiciones normativas' en Eugenio et al, Problemas lógicos en la teoría y práctica del derecho, Madrid: Fundación Coloquio Jurídico Europeo, pp. 27-74

Bulygin, Eugenio, 1991: 'Sentencia judicial y creación de derecho', en Alchourrón, Carlos y Bulygin, Eugenio, Análisis lógico y derecho, Madrid: Centro de Estudios Constitucionales, pp. 355-370.

Bulygin, Eugenio, 2005: 'En defensa de El Dorado. Respuesta a Fernando Atria', en Atria, Fernando. et al, Lagunas en el derecho, Madrid: Marcial Pons, pp. 73-86

Caracciolo, Ricardo, 1994: 'El concepto de Laguna: ¿Descripción o prescripción?' en La noción de sistema en la teoría del derecho, pp. 25-34, México: Fontamara

Dworkin, Ronald, 1977: 'Hard Cases', en Taking Rights Seriously, Cambridge: Harvard University Press

Gardner, John, 1988: 'Concerning Permissive Sources and Gaps', Oxford Journal of Legal Studies 8.

Honoré, Tony, 1987: Making Law Bind, Oxford: Oxford University Press

Kelsen, Hans, 1979, Teoría pura del derecho, 2a edición (Trad. De Vernengo, R.) México: UNAM

Kelsen, Hans, 1991: General Theory of Norms (Trad de M. Hartney), Oxford: Oxford University Press,

Kelsen, Hans, 1992: Introduction to the Problems of Legal Theory, (Trad. de Paulson, S.), Oxford: Oxford University Press

LAporta, Francisco, 2007, El Imperio de la Ley: Una visión actual, Madrid: Trotta

Larenz, Karl, 1980: Metodología de la ciencia del derecho, 4ta edición, (Trad. De Rodríguez Molinero), Barcelona: Ariel

Ramos Pascua, José A., 2017: 'Lagunas del derecho y positivismo jurídico' en Doxa 40, pp. 50-57

Lewis, David, 1979: 'A Problem about Permission', en Saarinen, Esa et al. (eds.), Essays in Honour of Jaakko Hintikka, pp. 163-174, Dordrecht: Reidel

Nino, Carlos, 1979: Algunos modelos metodológicos de 'ciencia' jurídica (Valencia, Venezuela: Universidad de Carabobo, 1979). Reimpreso en 1995, México: Fontamara (México).

Mazzarese, Tecla, 2002: 'Permisión fuerte y permisión débil: notal al margen', en Navarro, Pablo y Redondo, Cristina eds), La relevancia del derecho, Barcelona: Gedisa

Raz, Joseph, 1970: The Concept of a Legal System, Oxford: Oxford University Press

Raz, Joseph, 1979: 'Legal Reasons, Sources and Gaps', en Raz, Joseph, The Authority of Law, Oxford: Oxford University Press, pp. 56-80 
Raz, Joseph, 1979: 'The Institutional Nature of Law', en Raz, Joseph, The Authority of Law, Oxford: Oxford University Press, pp. 106-123

Raz, Joseph: 1990 Practical Reason and Norms, 2. ${ }^{\mathrm{a}}$ edición, Princeton: Princeton University Press

Rodríguez, Jorge, L., 2002: Lógica de los sistemas jurídicos, Madrid: Centro de Estudios Constitucionales

Ruiz Manero, Juan, 2005: 'Algunas concepciones del derecho y sus lagunas' Atria, Fernando. et al, Lagunas en el derecho, Madrid: Marcial Pons, pp. 103-126

Ruiz Manero, Juan, 2015: 'Sistema jurídico: lagunas y antinomias' en González Lagier, Daniel (ed), Conceptos básicos del derecho, Madrid: Marcial Pons

Schauer, Frederick, 1991: Playing by the Rules, pp. 53-62, Oxford: Oxford University Press

Soeteman, Arend, 1989: Logic in Law, Dordrecht: Kluwer

Ross, Alf, 1968: Directives and Norms, Londres: Routledge \& Kegan, Paul

Von Wright, G.H., 1968: An Essay in Deontic Logic and the General Theory of Action (Helsinki/ Amsterdam: Acta Philosophica Fennica, 1968).

Von Wright, G.H., 1984: ‘The Logic of Predication' en von Wright, G. H., Truth, Knowledge and Modality, Oxford: Oxford University Press

Von Wright, G.H., 1995: 'Analytical Philosophy: A Historico-Critical Survey', en von Wright, G. H., The Tree of Knowledge, New York: Brill

Wilson, Aida, 1994: 'Hans Kelsen -Introduction to the Problems of Legal Theory- Book Review' en Utilitas 6 